\title{
Japanilaisen noviisiopettajan näkökulma japanilaiseen ja suomalaiseen elinikäiseen oppimiseen
}

\author{
Japanilaiset yliopistot panostavat nykyisin aikuisopiskelijoihin \\ kokopäiväopiskelijoina. Japanissa on maailman alhaisin syntyvyys, ja \\ yliopistot kilpailevat uusista opiskelijoista. Noin 80 prosenttia suurten \\ ikäluokkien työntekijöistä, jotka olivat rakentamassa sodan jälkeistä \\ hyvinvointia, haluaisi jatkaa työntekoa eläkeiän jälkeenkin. Ikäihmisille \\ elinikäinen oppiminen on keino pysyä aktiivisina kansalaisina ja tuoda \\ elämään "ikigai 'ta", elämäniloa. Yliopistot siis ottavat aikuisopiskelijoita \\ niin yhteiskunnallisista syistä kuin lisätäkseen opiskelijamääriään.
}

JAPANIN HALLITUKSET ovat jo pitkään edistäneet eri toimenpitein elinikäistä oppimista. Kerromme tässä japanilaisesta näkökulmasta elinikäiseen oppimiseen sekä vertailemme kyselytutkimuksen avulla kokopäivätoimisia yliopisto-opiskelijoita ja avoimen yliopiston opiskelijoita Suomessa.

Kyselytutkimuksen lähtökohtana oli tilanne, jossa japanilainen yliopisto-opettaja kohtasi ensi kertaa suomalaisen avoimen yliopiston aikuisopiskelijaryhmän omassa opetustyössään. Hänellä oli viiden vuoden työkokemus yliopistossa opettamisesta, mutta työskenteleminen aikuisopiskelijoiden ${ }^{1}$ kanssa oli uutta: Tulisiko yliopisto-opiskelijoita ja aikuisopiskelijoita opettaa samalla tavalla ja jos ei, niin miten aikuisopiskelijoita tulisi opettaa?

Tämä kysymys on perustavanlaatuinen jokaiselle ensikertalaiselle opettajalle. Tutkimukset osoittavat, että kokeneillakin opettajilla on vaikeuksia selittää omaa opetusosaamistaan ja että hiljaista tietoa on hankala artikuloida ja jakaa (Shim and Roth 2007). Yliopisto-opettajilla ei välttämättä ole valmiuksia kohdata aikuisopiskelijoita, niin kokeneita kuin nuorempien opiskelijoiden kanssa työskentelyssä he olisivatkin. Heillä siis saattaa olla samanlaisia vaikeuksia kuin tässä raportoitavalla noviisiopettajalla.

Vertailemme tässä artikkelissa suomalaisen avoimen yliopiston opiskelijoiden ja yliopisto-opiskelijoiden ominaisuuksia ja niistä johtuvia pedagogisia vaatimuksia japanilaisen nuoren opettajan yritykseen ja erehdykseen pohjautuneen opetustyön perustalta. Nämä eri opiskelijaryhmät osallistuivat sisällöltään identtiselle kurssille ja heillä oli sama "noviisiopettaja". 
Tutkimusaineistona on kysely sekä otteena opettaja oman työnsä tutkijana -tyyppinen lähestymistapa.

\section{JAPANILAISTA NÄKÖKULMAA ELINIKÄISEEN OPPIMISEEN}

Aikuiskasvatus-lehdessä pohdittiin japanilaista korkeakoulujärjestelmää ja sen suhdetta työelämään muutama vuosi sitten (Parjanen 2006). Siinä Parjanen hämmästeli muiden muassa yliopistojen opiskelijavalintoja. Tässä jatkamme japanilaisen järjestelmän ja opiskelijavalintojen muuttumisen tarkastelua näkökulmanamme aikuisopiskelijat.

Koska elinikäinen oppiminen on katsottu portiksi 2000-luvulle (UNESCO 1996), Japanin hallitukset ovat pyrkineet edistämään elinikäistä oppimista jo useiden vuosikymmenien ajan. Kansallinen koulutusneuvosto (Central Education Council) julkaisi 1981 raportin Elinikäisestä koulutuksesta, mikä johti sekä julkisella että yksityisellä sektorilla useanlaisiin toimenpiteisiin elinikäisen oppimisen toteutumiseksi. Raportissa erityisesti kehotettiin yliopistoja avaamaan kurssejaan aikuisopiskelijoille. Hallitus laati suunnitelman yliopistoon sisäänpääsyn joustavuuden lisäämiseksi ja pääsykoejärjestelmän kehittämiseksi perustamalla jatkokoulutuksen edistämisen neuvoston ja laatimalla vuonna 1991 kaksi raporttia: Yliopistokoulutuksen parantamisesta ja Akateemisia oppiarvoja myöntävän instituutin perustamisesta. Näiden seurauksena yliopistot ottivat käyttöön korkeakoulutuksen aikuiskiintiöt. Useasti aikuisopiskelijat käyvät työssä, heillä on työelämäkokemusta eikä heillä ole samassa määrin aikaa valmistautua pääsykokeisiin kuin tavanomaisilla opiskelijoilla. Vuonna 201072 prosenttia yliopistoista $(\mathrm{N}=524)$ käytti erityisjärjestelyjä aikuisopiskelijoiden sisäänottamisessa (Ministry of Education, Culture, Sports, Science and Technology, Japan, MEXT 2010).

Kuten monen muunkin maan, Japanin nykyisen hallituksen päämääränä on alentaa työttömyyttä ja lisätä työllisyyttä. MEXTin (2007) raportin Uuden ajan toimenpiteet elinikäisen oppimisen edistämiseksi mukaan osa-aikatyöläisten, syrjäytyneiden ja keski-ikäisten uudelleen työllistyminen on ongelmallista. Raportin mukaan on erityisen tärkeää aktivoida elinikäisen oppimisen avulla kaikkia yhteiskunnan kansalaisia.

\section{ELINIKÄISEN OPPIMISEN}

\section{YHTEISKUNNALLISISTA TAUSTOISTA}

Nykyisin työntekijä ei voi olla varma työpaikkansa säilyvyydestä koko työiän ajan. Niinpä työntekijöiden edellytetään olevan kiinnostuneita uuden oppimisesta missä iässä tahansa. Hallitus haluaa tukea tätä kansallisen tuottavuuden nimissä. Elinikäinen oppiminen onkin saanut Japanissa paljon näkyvyyttä. Erään tutkimuksen mukaan elinikäisen oppimisen tunnettuus on vuosittain lisääntynyt erityisesti 40-60-vuotiailla (Cabinet Office, Government of Japan, 2008). Niiden yliopistojen määrä, jotka järjestävät "kokai koza" -kurssin² aikuisopiskelijoille, on viisinkertaistunut vuodesta 1967 (137) vuoteen 2010 (687). Aikuisopiskelijoiden määrä on kasvanut samana ajanjaksona 78 000:sta 1,1 miljoonaan (Kansallinen koulutusneuvosto 2010). MEXTin tekemän selvityksen mukaan suosiotaan nostavat kurssit, jotka koskevat kansainvälisiä suhteita, ympäristökysymyksiä ja vieraita kieliä, samoin kurssit, jotka ovat kohdennettuja naisopiskelijoille (MEXT 2005).

Nykyisin japanilaiset yliopistot panostavat aikuisopiskelijoiden kokopäiväopiskeluun. Japanissa on maailman alhaisin syntyvyys (WHO 2011) ja yliopistot kilpailevat uusista opiskelijoista. Ikärakenne on nopeasti kallistumassa vanhoja ikäluokkia kohti. Yli 60-vuotiaiden määrä verrattuna nuorten määrään on maailman korkein (WHO 2011). Suurten ikäluokkien joukkoeläköityminen on alkoi vuonna 2007. Noin 80 prosenttia suurten ikäluokkien työntekijöistä, jotka olivat rakentamassa sodan jälkeistä hyvinvointia, haluavat jatkaa työntekoa eläkeiän jälkeenkin. Niille ikäihmisille, jotka haluavat olla aktiivisia kansalaisia iäkkäämpinäkin, elinikäinen oppiminen voisi olla yksi tapa tuoda elämään "ikigaita", elämänintoa. Yliopistot siis sisäänottavat aikuisopiskelijoita, ei yksistään yhteiskunnallisista syistä, vaan myös opiskelijamäärän lisäämiseksi.

Yksi tunnetuimmista elinkäistä oppimista edistävistä yliopistoista on Japanin avoin yliopisto. Se perustettiin vuonna 1983 kansalliseksi instituutioksi. Nyttemmin on ilmaantunut aikuisopetukseen erikoistuneita verkkoyliopistoja. Waseda-yliopiston 'e-school' aloitti toimintansa vuonna 2003 Japanin ensimmäisenä, kokonaan verkossa suoritettavia tut- 
kintoja tarjoavana instituutiona. Yashima Gakuen -yliopisto perustettiin vuonna 2004 tutkintoja ja pätevyyksiä tarjoavaksi, verkossa toimivaksi avoimeksi yliopistoksi. Muita vastaavia ovat Cyber University (2007) ja Business Break Through (BBT) (2010). Yksi nykyajan japanilaisen aikuiskasvatuksen piirteistä on, että paikallishallinnot eri puolilla maata yhdessä yliopistojen ja muiden koulutusinstituutioiden kanssa perustavat elinikäistä oppimista edistäviä konsortioita. Esimerkiksi Setagayan kaupinginosa Tokiossa ylläpitää Setagaya e collegea, johon kuuluu neljä paikallista yliopistoa sekä paikallinen opetushallinto. College tarjoaa verkko-opintoja sekä paikallisesti että laajemmaltikin.

Näin yliopistot ovat avautuneet laajemmalle yleisölle elinikäisen oppimisen kautta. Yliopistolaisille on kuitenkin haastavaa, miten opettaa aikuisopiskelijoita. Yliopistot eivät kilpailutilanteen vuoksi jaa kokemuksiaan aikuisopetuksesta. Usein opettajat opettavat aikuisopiskelijoita samalla tavoin kuin muita opiskelijoita, koska heillä ei ole tietämystä tavoista lähestyä aikuisopiskelijoita (Kurita 2008). Opetusmenetelmistä ei riittävästi keskustella eikä niitä kehitetä yhdessä (Kurita 2008; Yoneoka 2011). Erillisiä aikuisopiskelijoita koskevia tutkimuksia on, mutta ei mitään kokonaisvaltaista laajempaa tutkimusta. Niinpä on katsottu mielekkääksi tutkia, miten elinikäisessä oppimisessa edistyneemmät maat - kuten Suomi - ovat järjestäneet koulutuksen.

\section{KYSELYTUTKIMUS VALOTTAA OPPIMISEN EROJA}

Toinen tämän artikkelin kirjoittajista opetti suomalaisen yliopiston englanninkielisellä kurssilla ja avoimen yliopiston saman nimisellä kurssilla vuonna 2010. Yliopiston kurssilla opiskelijoita oli 23 (keskiikä 22,1), joista kaksi suomalaista ja loput vaihtoopiskelijoita eri maista. Avoimen yliopiston kurssilla oli 12 opiskelijaa (keski-ikä 42,8). Kurssien sisältö oli sama ja ne järjestettiin läsnäolo-opintoina. Kurssilla oli myös käytössä verkkoalusta, jolla tiedotettiin, ladattiin kurssitehtäviä, annettiin palautetta ja jolle oli tallennettuna kurssin materiaaleja. Kummallekin opiskelijajoukolle tehtiin taustatietoja ja asenteita mittaava kysely. Opiskelijoilla oli myös kotitehtävänä pohtia itseään opiskelijana, motivaatiotaan ja syytä opiskeluun sekä heidän omaa rooliaan opiskelijajoukossa. Lisäksi he tarkastelivat median ja sen käytön nykytilannetta.

Seuraavissa kappaleissa esitämme aineistolainauksia. Ne ovat suomenkielisten opiskelijoiden ja muiden englantia ei-äidinkielenään puhuvien englanniksi kirjoittamia. Olemme säilyttäneet ne alkuperäisinä.

\section{Alkukysely}

Alkukysely koostui 33 väittämästä ja se lähetettiin edellä mainituille kahdelle opiskelijaryhmälle. Vastaajia oli yliopisto-opiskelijoissa 21 ja avoimen yliopiston ryhmässä 10. Vastaajat arvioivat asteikolla 1-5 motivaatiota kurssille osallistumiseen, opintojen sisältötoivomuksia, odotuksia opinnoilta, syytä opintoihin osallistumiseen ja yliopistoon kohdistuvia odotuksia.

Tilastollisesti merkittäviä eroja ryhmien välillä löytyi motivaatiosta kurssille, opintoihin osallistumisen syissä sekä yliopistoon kohdistuvissa odotuksissa. Yliopisto-opiskelijolla oli selkeästi opintopisteiden hankintaan kohdistuvaa motivaatiota, sosiaalisia tarpeita ja asiantuntijatiedon tarvetta enemmän kuin aikuisopiskelijoilla. Samoin heille oli aikuisopiskelijoita tärkeämpää päästä yliopiston tarjoamien resurssien, kuten kirjaston ja verkkopalvelujen äärelle. Tästä tulkitsimme, että yliopisto-opiskelijat ovat tavoiteorientoituneempia ja avoimen yliopiston opiskelijat prosessiorientoituneempia. Viimeksi mainitut opiskelevat omasta kiinnostuksesta yksilölliseen tyyliin.

\section{Loppukysely}

Viimeisellä tapaamiskerralla kummallakin opiskelijaryhmällä teetettiin kysely, joka koostui 10 väittämästä. Ne koskivat mm. yleistä tyytyväisyyttä kurssia kohtaan sekä sisällön ja toteutustavan mielekkyyttä. Kahdeksan avoimen yliopiston kurssin ja 13 yliopistokurssin opiskelijaa vastasi kyselyyn. Tilastollisesti merkitseviä eroja ei ryhmien väliltä löytynyt. Suuntaa antavana voidaan ehkä pitää sitä, että aikuisopiskelijoiden keskiarvo väittämissä "Minulla oli tarpeeksi informaatiota aiheesta", "Digitaalista materiaalia oli riittävästi ja "Kurssin taso oli sopiva" oli 0.5 alempi 
kuin yliopisto-opiskelijoiden vastaavat. He näyttävät suhtautuvan yliopisto-opiskelijoita kriittisemmin opintoihinsa. Taustalla saattaa olla heterogeenisen ryhmän vaihtelevat intressit.

\section{HAVAINTOJA OPISKELIJAIN REFLEKTOINNISTA}

Itseään opiskelijana koskeva reflektointi tuotti seuraavia havaintoja:

\section{Taustat:}

Opiskelijaryhmien taustat vaihtelivat. Lähes jokainen yliopisto-opiskelijoista haluaa työskennellä tulevaisuudessa koulussa joko opettajana, esikoulun opettajana tai sosiaalityöntekijänä. Joillakin heistä oli lyhytaikaisia työkokemuksia näistä ammateista. Avoimen yliopiston opiskelijoilla oli ammattinimikkeitä laidasta laitaan kuten IT-alan työntekijä, henkilöstöjohtaja, opettaja, insinööri, entinen opettaja ja lisäksi mukana oli työttömiä.

\section{Opiskelumotivaatio:}

Yliopisto-opiskelijoiden motivaatiot opiskeluun olivat melko yhteneväiset kuten kiinnostus kurssin sisältöä kohtaan ja tulevia ammatilliset tarpeet. Monilla yliopisto-opiskelijoilla olikin urasuuntautunutta orientaatiota.

"I am learning because I want to achieve my aim to be able to help other people with my knowledge about education, methods and skills." (naisyliopisto-opiskelija, 22)

"I need to have plenty knowledge as I am going to work as a teacher. So I need to be informed about everything around me and broadcast the knowledge to the children." (naisopiskelija, 22)

"... One part of my tasks is development of learning solutions. When I started in my company most of the training courses were face to face but now the cost pressure is high and we have almost constant travel ban in the company. Distance learning has become most favourable method nowadays. That's also the reason why I decided to attend this training. I would like to understand what should be taken into account from learning point of view, what are the new possibilities and what might be ahead of us in future." (avoimen ylio-opiston opiskelija, 51)
"I'm studying because I want to have some meaningful things to do. Besides, I need media education at school because I work with young people who use new media everyday. I am not so good with computers." (avoimen yliopiston opiskelija, ammatiltaan opettaja, 62)

\section{Opiskeluvälineiden preferointi:}

Opinnoissa käytettävien välineiden ja median preferointi vaihteli yksilöittäin. Näyttää tosin siltä, että aikuisopiskelijat pitivät perinteisen median (kirjat, muistiinpanovihot) käytöstä enemmän kuin muunlaisista opiskeluvälineistä.

"I usually learn through books, because I can write and highlight the main ideas and also my own ideas. But books usually are about ideas very general or definitions... I like learning with media I can touch. On the other hand, I prefer videos to have a main idea quick and have in context some concepts. A radio or something similar do not help me because I need see some images with the words." (naisyliopisto-opiskelija, 24)

"I am a practical learner that means I can understand something new, better when I can see, how I have to do it, do it by myself or try to do a picture of it. If I have to learn theory, the best way form me is to combine it with the reality." (vuotias naisyliopisto-opiskelija, 21)

"What comes to the learning solutions and methods, in general, I prefer to read 'traditional' books. Naturally this is not black and white." (Naisaikuisopiskelija)

"For me the easiest way to learn is to write down important things" (avoimen yliopiston opiskelija, ammatiltaan opettaja, 62)

\section{HETEROGEENINEN JOUKKO TARJOAA OPETTAJALLE HAASTEITA}

Miten siis ottaa huomioon aikuisopetuksen erityispiirteet tämän tutkimuksen perusteella. Esitämme tulosten koontaa ja johtopäätöksiä sekä muutamia käytännön ehdotuksia. 


\section{Opiskelijataustojen moninaisuus}

Keskeinen aikuisopiskelijajoukon piirre, kuten Field (1982) on todennut, on opiskelijoiden taustojen vaihtelevuus. Tämä ei koske pelkästään ikää vaan myös intressejä, tottumuksia sekä oppimis- ja työkokemuksia. Se koskee erityisesti aiempaa tietämystä ja osaamista, minkä avoimen yliopiston avoimuus tuo mukanaan. Kuvaamamme tutkimuksen avoimen yliopiston opiskelijajoukko koostui niistä, jotka opiskelivat lähinnä harrastuksena, ja niistä, joilla oli jo runsaasti aiempaa tietämystä ja osaamista. Esimerkiksi jotkut opiskelijat pyysivät opettajaa käyttämään yksinkertaisempaa kieltä hänen selostaessaan podcasteja etäopiskelun välineenä - he eivät olleet täysin ymmärtäneet käytettyä kieltä. Toisaalta eräs opiskelija valitti palautteessaan, että hän olisi kaivannut pidemmälle meneviä teknisiä ratkaisuja ja käytännön esimerkkejä niistä. Opiskelijoiden tietämyksessä oli hajontaa. Iällä näytti olevan tässä merkitystä, koska vanhemmat opiskelijat näyttivät kompastelevan teknisissä asioissa.

\section{Avoin keskusteluilmapiiri ja yksilöllinen opiskelu}

Avoimen yliopiston opiskelijoilla oli positiivinen ja kannustava suhtautuminen omien työkokemustensa jakamiseen ryhmässä. He toivat usein esiin konkreettisia esimerkkejä omista kokemuksistaan ja käyttivät pragmaattisia puheenvuoroja opiksi muille. Nämä opiskelijat olivat yliopisto-opiskelijoita tottuneempia toimimaan heterogeenisessa ryhmässä. Samalla he arvostivat yksilöllistä opiskelutyyliä. Esimerkiksi jotkut aikuisopiskelijoista valittivat, että he eivät voi osallistua ryhmätyöskentelyyn verkossa luentojen ulkopuolella, koska heidän työaikataulunsa eivät mahdollista sitä. Tämä puolestaan ruokkii yksilöllistä tyyliä. Kuten edellä esitetyt tulokset osoittavat, yliopisto-opiskelijoiden yksilöllisyys ei ollut yhtä keskeisessä asemassa.

\section{Opetusmenetelmät}

Kun otetaan huomioon opiskelijoiden taustat, opetuksessa on tasapainoiteltava yleistä ja erityistietämystä sisältävien oppisisältöjen välillä. Tarvitaan niin yksityiskohtaista, helppokielistä selitystä kuin asiantuntemustietämystäkin. Oppimateriaaleja tulisikin laatia kummallekin tasolle, mikä auttaa opiskelijoita etenemään omaan tahtiinsa. Tulisi myös ottaa huomioon opiskelijoiden mediapreferenssit ja niiden tuomat mahdollisuudet omien aikataulutusten laatimiseksi.

Opiskelijoiden työ- ja aiemmat opiskelukokemukset kannattaa hyödyntää. Joillakin aikuisopiskelijoilla oli tässä mielessä runsaasti annettavaa, enemmän kuin opettajalla, omilta erityisaloiltaan. Opiskelijoita kannattaakin keskusteluttaa. Näin saadaan syntymään moniäänistä keskustelua ja aktivoidaan opiskelijoita. Tässä on kuitenkin otettava huomioon aikuisopiskelijoiden erityispiirre, jonka mukaan oppituntien ulkopuolinen keskustelu ei käytännön syistä välttämättä onnistu. On siis mietittävä yksilöllisen työskentelyn ja ryhmätyöskentelyn tasapanoa ja ylipäätään kiireisillä aikuisopiskelijoilla teetetyn työn määrää. Alkukartoitus opintojen alussa on yksi keino onnistua tässä.

Vaikka tässä artikkelissa esitetyt tutkimustulokset eivät ole mullistavia, katsoimme asialliseksi avata keskustelua muiden yliopistossa ja avoimessa yliopistossa opettavien opettajien kokemuksista. Vaikka japanilaisen elinikäisen oppimisen pohjalta ei voikaan suoraan tarkastella suomalaista vastaavaa johtuen kulttuurisista ja yhteiskunnallisista eroista, katsomme sen kuitenkin antavan erilaista näkökulmaa sekä suomalaiseen että japanilaiseen aikuisopiskeluun ja -opetukseen.

\section{LOPUKSI}

Kuvaamamme kyselytutkimus oli kahden opiskelijoukon tapaustutkimus. Tutkimusta tulisi jatkaa runsaammalla opiskelijamäärällä ja ottaa mukaan myös opettajia ja koulutuksen järjestäjän edustajia. Lopuksi esitämme muutaman jatkotutkimusteeman:

Japanin ja Suomen elinikäisen oppimisen ja aikuiskoulutuksen vertailevaa tutkimusta tulisi jatkaa, sekä koulutuspoliittista että kenttätutkimusta.

Olisi syytä pohtia, miten Suomesta saatuja tuloksia voisi hyödyntää japanilaisessa elinikäisessä oppimisessa.

Opettaja- ja tutkijavaihtoa näiden kahden maan välillä tulisi lisätä teemaan liittyen. 


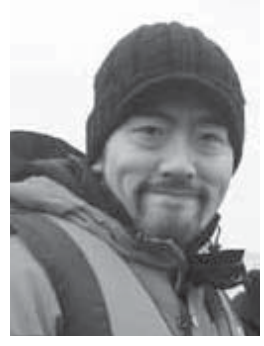

Yutaro Ohashi

tohtoritutkija

Helsingin yliopisto

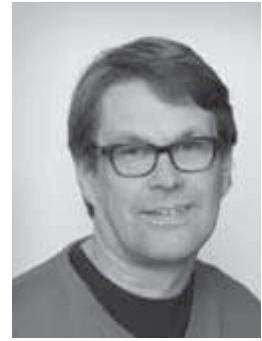

Heikki Kynäslahti

yliopistonlehtori

Helsingin yliopisto

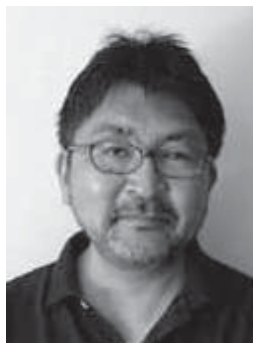

Fumitoshi Kato

professori

Keio-yliopisto, Japani

\section{KIITOKSET}

Haluamme kiittää tutkimukseen osallistuneita henkilöitä. Yutaro Ohashi on saanut Kitano Foundation of Lifelong Integrated Education -rahastolta tutkimusapurahan tämän tutkimuksen suorittamiseen.

\section{LÄHTEET}

Field, J. (1982). Characteristics of OU students. Teaching at a Distance Research Supplement (No. 1), Milton Keyens.

Kansallinen koulutusneuvosto (Central Education Council). (2010). Atarashii zidai wo kirihiraku shougai gakushuu no shinkou housaku ni tsuite -Chi no junkan shakai no kouchiku wo mezashite- [in Japanese] A policy for promoting lifelong learning for the new era: toward building knowledge circulating society (a report)

Kurita, Michiharu. (2008). Kyouyou kyouiku to key competency [Liberal Education and Key Competencies (Essays on Liberal Education); in Japanese]. Journal of the Society for General Academic and Cultural Research 12/13, 81-97.

MEXT 2010. Gakkou kihon chousa [A fundamental investigation on schools; in Japanese]. http://www. mext.go.jp/b_menu/toukei/chousa01/kihon/kekka/k_ detail/_icsFiles/afieldfile/2010/12/21/1300352_2.pdf

MEXT 2007. White Paper on Education, Culture, Sports, Science and Technology

MEXT 2005. White Paper on Education, Culture, Sports, Science and Technology

Nomura Research Institute 2005. http://www.nri.co.jp/ news/2005/051118 1.html

Parjanen, M. (2006) Aikuiset ihanneopiskelijoita. Aikuiskasvatus 2006(1), 71-73.

Shim, H.S., \& Roth, G.L.( 2007). Sharing Tacit Knowledge Among Expert Teaching Professors and Mentees: Considerations for Career and Technical
Education Teacher Educators. Journal of Industrial Teacher Education, 44(4), 5-28.

UNESCO (1996). Learning the treasure within.

WHO (2011). World Health Statistics 2011

Yoneoka, Yumi (2011). Nihon ni okeru seijin kyouiku houhouron no kouzou ni kansuru ichi kousatsu [A Study on the Structure of Adult Education Methodologies in Japan; in Japanese]. Journal of lifelong education and libraries 10, 75-84.

\section{VIITTEET}

1 Suomessa aikuisikä kattaa ikävuodet 30:stä ylöspäin. Tätä määritelmää käytetään tässä artikkelissa myös aikuisopiskelijaan.

2 Kurssi on avoin ja vastaa lähinnä Suomen Studia generalia -tyyppistä koulutustilaisuutta. 